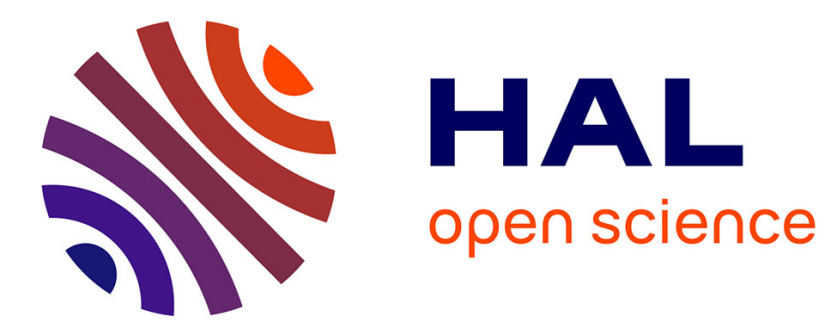

\title{
Global Vector Control Guidelines - The Need For Co-Creation
}

\author{
Gregor Devine, Hans J Overgaard, Richard E. Paul
}

\section{To cite this version:}

Gregor Devine, Hans J Overgaard, Richard E. Paul. Global Vector Control Guidelines - The Need For Co-Creation. Trends in Parasitology, 2019, 35 (4), pp.267-270. 10.1016/j.pt.2018.12.003 . hal02747499

\section{HAL Id: hal-02747499 \\ https://hal.science/hal-02747499}

Submitted on 22 Oct 2021

HAL is a multi-disciplinary open access archive for the deposit and dissemination of scientific research documents, whether they are published or not. The documents may come from teaching and research institutions in France or abroad, or from public or private research centers.
L'archive ouverte pluridisciplinaire HAL, est destinée au dépôt et à la diffusion de documents scientifiques de niveau recherche, publiés ou non, émanant des établissements d'enseignement et de recherche français ou étrangers, des laboratoires publics ou privés.

\section{다)(1) $(5$}

Distributed under a Creative Commons Attribution - NonCommerciall 4.0 International 


\section{Global vector control guidelines - the need for co-creation}

2

3 Gregor J. Devine ${ }^{1}$, Hans J. Overgaard ${ }^{2}$, Richard E. Paul ${ }^{3,4^{*}}$ (alphabetical order)

4

$5{ }^{1}$ Mosquito Control Laboratory, QIMR Berghofer Medical Research Institute, Brisbane, 6 Queensland 4006, Australia.

$7 \quad{ }^{2}$ Norwegian University of Life Sciences, Ås, Norway.

$8{ }^{3}$ Institut Pasteur, Functional Genetics of Infectious Diseases Unit, Department of Genomes 9 and Genetics, 75015 Paris, France

${ }^{4}$ Centre National de la Recherche Scientifique (CNRS), Génomique évolutive, modélisation et santé UMR 2000, 75724 Paris Cedex 15, France.

* Correspondence : rpaul@pasteur.fr

\section{Keywords (2-6)}

Mosquito control, co-creation, inter-sectoral collaboration, WHO Prequalification

\section{Abstract}

In response to the global expansion and re-emergence of vector-borne diseases, WHO launched the Global Vector Control Response program in 2017. The aim is to strengthen vector control through increased capacity, innovation, improved surveillance, better coordination and integrated action. Will this new approach overcome the failings of previous initiatives? 


\section{The advent of the 2017-2030 Global Vector Control Response}

The flat-lining of the global reduction of malaria, the recent chikungunya and Zika pandemics, the unabated spread of dengue and the re-emergence of yellow fever come as a sharp reminder of the continuing threats posed by mosquito-borne diseases [1,2]. National public health authorities are facing an ever-increasing disease burden but with little ability to define the extent of the challenge, the tools that might be used in response or the mitigation strategies that would effectively integrate local stakeholders. In response to this escalating problem and increasing criticism of global vector control capacity, WHO has attempted to galvanize mosquito control strategies by redrafting the integrated vector management plan [3,4]. This 2017-2030 Global Vector Control Response (GVCR) aspires to reduce vectorborne disease mortality by $75 \%$ and incidence by $65 \%$ by 2030 and halt the further spread of vector borne disease to new countries by 2025 . The GVCR aims to strengthen the foundations of vector control and improve implementation (Figure 1). Here we discuss the feasibility of the approach and suggest potentially productive avenues to explore.

\section{Innovation, efficacy and implementation}

In 2017, in a bid to accelerate vector control product evaluation and harmonise pathways with those in place for vaccines and medicines, the existing WHO Pesticide Evaluation Scheme (WHOPES) was replaced by the WHO Prequalification Team for Vector Control (PQT-VC). It is responsible for the safety, efficacy and quality of vector control products and is supported by the Vector Control Advisory Group (VCAG), which assesses the public health value of new tools and paradigms (Figure 2). As our existing vector control tools are inadequate [5,6], VCAG's role in evaluating new tools is clearly a corner stone of the innovation required to achieve the ambitious goals of the GVCR. Without effective tools with appropriate training and education to go along with deployment, the pillars of the GVCR (engage, strengthen and scale) will crumble.

One major development is to insist that vector control tools and methodologies have proven epidemiological efficacy, preferably in the form of two randomised control trials (RCTs), each repeated over two transmission seasons. These trials are essential for proving the public health benefit of interventions but we must also recognise that they are extremely expensive and time-consuming. Whilst the Global Fund has supported such trials for malaria interventions, no such financial backing exists for other vector-borne diseases. Aedes-borne 
diseases in particular, such as dengue, will be problematical because of their unpredictability in time and space, even in endemic countries. Without sufficient infections an epidemiological impact cannot be determined, which will confound the best efforts of trial designers to deliver definitive epidemiological results. Novel approaches for dealing with Aedes do exist, but are currently not recommended for full-scale deployment and only to be implemented as pilot interventions ${ }^{\mathrm{i}}$. The risk therefore is that the delivery of new tools and strategies will be glacially slow, frustrating innovators and leaving national control programs to manage disease with conventional tools that also have a very limited evidence base. To alleviate the onerous nature of RCTs, the VCAG guidelines do allow consideration of nonrandomized trials [7], but this could be further relaxed for arboviral disease in acknowledgement of their increased costs. Interim recommendations, in the absence of a complete epidemiological package, were once available under the WHOPES scheme.

A crucial factor determining the number of trials required to develop a new and reliable tool box for vector control is careful rationalisation of product classes and identification of "first in class" prototypes. The large number of vector control innovations and new paradigms under consideration will need to be categorised carefully, in order to maximise the speed at which products come through the pipeline [8]. New products that fall under an existing product class with an extant WHO policy recommendation will follow the Prequalification Pathway, under which epidemiological trials are not required (e.g. pyrethroid-treated bednets with similar entomological impact to the "first in class" product). Interventions deemed to function under a new paradigm will have to be evaluated for their public health claims. Many current product classes in the pipeline have some remarkably narrow definitions. Is a pyrethroid net treated with a synergist really a new paradigm? Is it necessary to list endectocidal interventions host by host? (i.e. a current listing states : "Systemic cattle treatment for vector control").

The pillars of the GVCR are built around Integrated Vector Management (IVM): the accepted model for many vector control programs that implement a number of management approaches simultaneously [9]. Perhaps epidemiological efficacy does not have to be established for every component of those programs. In some instances it might make more sense to prove entomological efficacy across a range of components and then carry out epidemiological trials on an integrated design (accepting that this would result in an endorsement for the entire strategy and not for any single component) $[10,11]$.

Whilst awaiting the proven efficacy of future tools, immediate mosquito management strategies are urgently required. This is especially the case for arboviral diseases. Currently, 
we are stuck in an outdated dengue vector control paradigm of fogging and larviciding with low impact due to poor implementation and ineffective insecticides. How to break the status quo? Improved surveillance and better deployment of currently available vector control tools is key. Whilst insecticide resistance is an issue for several currently used products, there are others that deserve attention, most particularly in the development of non-insecticidal approaches and application methodology [11,12]. Methodological aspects have been largely neglected and yet should enable significant improvements in impact, for example targeted indoor residual spraying to reduce the time and effort required to protect selected disease and transmission hotspots [13].

There is no "one size fits all" paradigm for any vector-borne disease. Local characteristics of transmission and vector ecology will drive the choice of tools. Strategy development must be executed at the country level and even within country for those with a de-centralised health system and varying environmental contexts. Operationally, the programs that result must be appropriate, feasible and cost-effective. Currently, there are evident problems of resourcing, training, community engagement, building an evidence base and retaining a positive expectation from the vector / disease control units [14]. This consequently leads to the implementation of sub-optimal programs that are draining precious resources from public health authorities. The continued inability of countries to develop appropriate strategies could be alleviated through re-assessment and co-development by stakeholders, who include innovators, the community, disease response and control units and policy makers (National Control Programs, WHO) and who currently fall back on poorly implemented traditional approaches with little expectation of impact.

Intra- and inter-sectoral collaborations: Co-creation of vector control tools and strategies

The importance of intra- and inter-sectoral collaborations (ISC) has been repeatedly emphasised as one of the keys to successful vector control strategies ${ }^{\mathrm{ii}}$ and yet beyond the Roll Back Malaria initiative, their added value remains unquantified [15]. The majority of current programs lack ISC and a vertical top-down decision-making process remains with little recourse to dialogue with communities. This is surprising for mosquito control, where the importance of community involvement is always advocated and clearly beneficial [15], but whose effective participation is rarely achieved and there is little guidance or dialogue with other stakeholders. Increased efforts to educate communities to take responsibility for disease 
mitigation are necessary but will require novel methods for engagement and incentivising communities. Community-based trapping schemes for monitoring mosquito populations at nationally representative scales for continuous assessment have been shown to be costeffective and may be a viable long-term sustainable option [16]. Likewise, one key component of recent Wolbachia-mediated approaches to control has been the inventive and energetic engagement with stakeholders [17].

Lack of resources is a central roadblock to the development and implementation of new strategies and one that impacts upon health care globally. Private sector involvement in malaria control has proven fructuous and yet is absent for other mosquito-borne diseases, despite the increase in arboviral epidemics and the concomitant demand for mosquito control products. The market for new products is rapidly expanding in Asia and the Americas and opportunistic investment and involvement by the private sector and enhanced corporate social responsibility might ease the financial shackles faced by governments and plug the gaps in funding required for product evaluations. Investment in new control paradigms will, however, likely remain hesitant unless all stakeholders can clearly see benefit.

What is needed is improved dialogue among national and international stakeholders to plan what is feasible with the resources available and to negotiate the minimal adequate solution. The paucity of proven tools and our limited grasp on what strategies will actually work mean that such negotiated planning must be based on simulated scenarios with included uncertainty margins. In this way a suite of potential scenarios adapted to the country and within-country sites can be budgeted and discussed. These can then be used to identify the key gaps and requirements through a process of co-creation, co-production and co-delivery. By trying to speed up and prioritise innovations with stakeholders, we may make development more affordable or at least define the market opportunity, thereby making investment, financial or otherwise, more attractive.

While we await the outcomes of more stringent evaluation processes, co-creation offers an imperfect, but necessary assessment of innovation and development. It emphasises the immediate needs of the end-user and will help prioritise the evaluation of new product classes. This more inclusive process is likely to ensure regional representation and community “ownership".

Greater interaction between research, industry, community and policy will improve the relevance and adoption of public health tools. This is crucial for the all-important scale-up of new strategies. Rather than simple provision of a guidebook, policy makers and innovators 
might better serve communities by considering strategies that are co-designed and coproduced. That dynamic and contextual process can explicitly address local and regional priorities around ecosystems, climate change, health risks and economics.

The vector control management agenda is formidable and despite substantial research efforts, control programmes remain little changed. Meanwhile, the global burden of vector-borne disease continues to increase. The global community is ill-equipped to face that threat and unsure of what to do given the long lead-in times for the evaluation of new public health tools. Perhaps it is time that, rather than relying solely on vertically communicated guidelines, governments and communities mobilise to develop their own pragmatic action plans, as was achieved in an integrated approach with community involvement [10], in full acknowledgement of their inevitable shortcomings but in recognition that the status quo cannot deliver. These action plans are bound to be integrated and based on the evidence base as it exists, however flimsy and however much it has to be based on entomological rather than epidemiological proofs. This surely must be an immediate consideration whilst waiting for the vector control panacea.

\section{Acknowledgements}

HJO and REP acknowledge support from the DENCLIM project (Research Council of Norway project no. 281077). We thank the reviewers for invaluable comments and suggestions.

\section{References}

1. Wilder-Smith A. et al. (2017) Epidemic arboviral diseases: priorities for research and public health. Lancet Infect Dis 17(3): e101-e6.2.

2. Ghebreyesus TA, Admasu K. (2018) Countries must steer new response to turn the malaria tide. Lancet pii: S0140-6736(18)32943-X.

3. World Health Organization. (2017) Framework for a National Vector Control Needs Assessment Geneva: World Health Organization. WHO/HTM/GVCR/2017.02.

4. World Health Organization. (2017) Global vector control response 2017-2030. ISBN 97892-4-151297-8. 
5. Reiner RC. et al. (2016) Quantifying the Epidemiological Impact of Vector Control on Dengue. PLoS Negl Trop Dis 10(5): e0004588.

6. Killeen G. et al. (2017) Developing an expanded vector control toolbox for malaria elimination BMJ Global Health 2: e000211.

7. World Health Organization. (2017) How to design vector control efficacy trials, guidance on phase III vector control field trial design. Geneva: World Health Organization; 2017. Licence: CC BY-NC-SA 3.0 IGO. WHO/HTM/NTD/VEM/2017.03

8. World Health Organization. (2018) Overview of product classes and prototype/products under Vector Control Advisory Group (VCAG) review for assessment of public health value WHO/CDS/VCAG/2018.03.

9. Marcos-Marcos J. et al. (2018) Impact, economic evaluation, and sustainability of integrated vector management in urban settings to prevent vector-borne diseases: a scoping review. Infect Dis Poverty 7(1):83.

10. Andersson N. et al. (2015) Evidence based community mobilization for dengue prevention in Nicaragua and Mexico (Camino Verde, the Green Way): cluster randomized controlled trial. BMJ 351:h3267.

11. Overgaard HJ. et al. (2016) A Cluster-Randomized Controlled Trial to Reduce Diarrheal Disease and Dengue Entomological Risk Factors in Rural Primary Schools in Colombia. PLoS Negl Trop Dis 10(11): e0005106.

12. Anders KL. et al. (2018) The AWED trial (Applying Wolbachia to Eliminate Dengue) to assess the efficacy of Wolbachia-infected mosquito deployments to reduce dengue incidence in Yogyakarta, Indonesia: study protocol for a cluster randomised controlled trial. Trials 19(1):302.

13. Vazquez-Prokopec GM. et al. (2017) Combining contact tracing with targeted indoor residual spraying significantly reduces dengue transmission. Sci Adv 3(2):e1602024.

14. Horstick O. et al. (2010) Dengue vector-control services: how do they work? A systematic literature review and country case studies. Trans R Soc Trop Med Hyg 104(6):379-86. 
15. Herdiana H. et al. (2018) Intersectoral collaboration for the prevention and control of

213 vector borne diseases to support the implementation of a global strategy: A systematic review. PLoS ONE 13(10): e0204659.

215

16. Sikaala CH. et al. (2014) A cost-effective, community-based, mosquito-trapping scheme that captures spatial and temporal heterogeneities of malaria transmission in rural Zambia. Malar J. 13:225.

17. O'Neill SL. et al (2018) Scaled deployment of Wolbachia to protect the community from Aedes transmitted arboviruses. Gates Open Res 2:36.

\section{Resources}

${ }^{\mathrm{i}}$ http://www.who.int/neglected_diseases/news/mosquito_vector_control_response/en/

ii http://www.who.int/heli/risks/vectors/malariacontrol/en/ iii http://www.who.int/vector-control/vcag/vcag-may2018-sustainabilityimprovement.pdf?ua=1

\section{Figure Legends}

Figure 1. WHO Global Vector Control Response framework. The GVCR aims to reduce the burden of all VBDs through vector control. This goal is to be achieved by building upon the foundations of enhanced vector control capacity and improved basic and applied research through four pillars of action [3].

Figure 2. WHO Prequalification evaluation Pathway for vector control products. To assess the public health value of new vector control tools, technologies and approaches submitted to WHO for evaluation, the following evaluation pathway will be applied ${ }^{\text {iii }}$. 

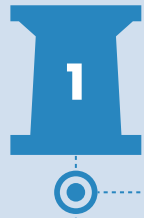

Strengthen inter- and intra-sectoral action and collaboration

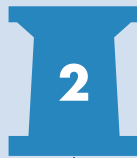

\section{Pillars} of action

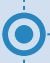

Engage and mobilize communities
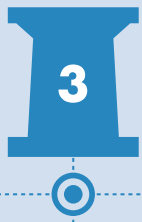

Enhance vector surveillance, and monitoring and evaluation of interventions
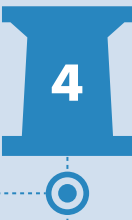

Scale up and integrate tools and approaches

\section{Foundation}

A Enhance vector control capacity and capability

B Increase basic and applied research, and innovation

\section{Enabling factors}

Country leadership

Advocacy, resource mobilization and partner coordination

Regulatory, policy and normative support 


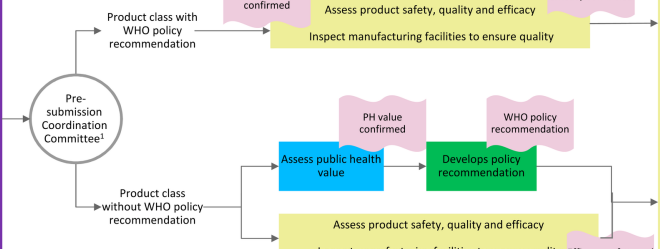

Inspect manufacturing facilities to ensure quality

Pre-qualify product

(product listing)

Inspect manufacturing facilities to ensure quality Efficacy, safety and quality confirmed 